\title{
The Grey Relational Analysis of the Allocation of S\&T Resources and Technological Progress in Guangdong
}

\author{
Zhong Jiayi ${ }^{1, *}$ \\ ${ }^{1}$ Guangzhou College of Technology and Business, Guangzhou, Guangdong 510850, China
}

\begin{abstract}
Using the relevant data of Guangdong Province from 2000 to 2019, the gray correlation analysis method is used to empirically study the relationship between the scale, structure, effect of regional scientific and technological resource allocation and technological progress. The empirical analysis results show that the scale of regional scientific and technological resource allocation has the highest correlation with technological progress. From the perspective of classification indicators, the gray correlation degree of $R \& D$ investment intensity is the highest at 0.8468 ; the gray correlation degree of the proportion of experimental development in $R \& D$ expenditure is the lowest, at 0.5071 . On the whole, the interactive relationship between the allocation of scientific and technological resources and technological progress in Guangdong Province is relatively obvious, and the allocation of scientific and technological resources has a strong driving force for social technological progress.
\end{abstract}

\section{INTRODUCTION}

Technology has become the core of this round of strategic games among major countries, and its degree of development is an important indicator of the overall competitiveness of a country or region. As the pioneer of China's reform and opening up, Guangdong is also the main battlefield for the country to participate in global economic governance and technological competition. It shoulders the important strategic task of building an international science and technology innovation center in the Guangdong-Hong Kong -Macao Greater Bay Area. Guangdong's economy is in a critical period of qualitative change in the conversion of new and old kinetic energy. How to make use of its advantages in innovation environment and innovation resources, rationally allocate scientific and technological resources, and drive breakthroughs and innovations in core technologies in related fields around the national key research and development plan, and improve the quality and efficiency of Guangdong's economic development.

\section{LITERATURE REVIEW}

As the core resource of regional innovation activities, scientific and technological resources include the sum of various scientific and technological elements such as manpower, material resources and financial resources invested to promote scientific and technological progress [1]. The allocation of scientific and technological resources is the dynamic management of scientific and technological resources within a certain time and space. It includes how to allocate various scientific and

\footnotetext{
*Corresponding author:gzgs_zhongjiayi@sina.cn
}

technological resources internally at the micro-level enterprise level, and also includes the national administrative department's macro-level allocation of scientific and technological resources in different industries, fields, and different industries. Hsieh et al. (2007) pointed out that the scale of government expenditure, labor, knowledge, capital, etc. are all important factors affecting the allocation of scientific and technological resources [2]. Adadi et al. (2013) pointed out that the optimal allocation of scientific and technological resources can provide enterprises with information resources to promote technological progress and economic development ${ }^{[3]}$. Shi Lei (2012) compared and analyzed the distribution of scientific and technological resources in various regions of our country, and put forward suggestions to promote the optimal allocation of resources ${ }^{[4]}$. Suri (2015) demonstrated the importance of spillover utility to the optimal allocation of scientific and technological resources from the perspectives of human, material, and coordination mechanism [5]. This article starts from the three dimensions of the scale, structure, and effect of the allocation of scientific and technological resources, and uses the gray correlation model to analyze the impact of the allocation of scientific and technological resources on the technological progress of Guangdong Province, and then provides a reference for relevant policy formulation.

\section{Research methods and index design}

The basic idea of gray correlation analysis is to try to find the numerical relationship between the various influencing factors in the system according to the degree of similarity or difference in the geometric shape of the 
sequence curve, that is, the gray correlation degree is used as a method to measure the degree of correlation between factors. Grey relational theory can quantify the trend of system development and determine which factors are the main factors and which are the secondary factors, so it is very suitable for dynamic process analysis. Indicator design needs to be based on the principles of systemicity, scientificity, and maneuverability, and summarize and refine the influencing factors according to the research objectives, so that the evaluation indicators can be standardized and systematized as much as possible, so as to make scientific and reasonable judgments and evaluations. The allocation of scientific and technological resources in Guangdong Province can be analyzed from the three dimensions of scientific and technological resources allocation scale, allocation structure, and allocation effect to comprehensively investigate the input, allocation and output of scientific and technological resources in the region. Taking into account the characterization and availability of data, the scale of scientific and technological resource allocation is mainly expressed by the amount of human and financial input, using the full-time equivalent of R\&D personnel (X1), and the proportion of local financial technology allocations in total local fiscal expenditures (X2), The proportion of R\&D expenditure in GDP (X3) is used as an evaluation indicator of the scale of allocation; the allocation structure of science and technology resources focuses on reflecting the type and distribution of R\&D funding, using basic research to account for the proportion of R\&D expenditure (X4), and applied research to $R \& D$ expenditure The proportion of $R \& D$ expenditure (X5) and the proportion of experimental development in R\&D expenditure (X6) are used as the evaluation indicators of the allocation structure; the allocation effect of scientific and technological resources mainly reflects the situation of scientific and technological output, and the number of invention patent applications per 10,000 population (X7) is used as the evaluation of the allocation effect index. The high-tech industry is a technology-intensive and knowledge-intensive type of industry. It is difficult to develop core technologies. The leading technology of the product must be at the forefront of the field. Therefore, the proportion of the output value of high-tech products in the total industrial output (X0) is used as technological progress. The higher the ratio, the more obvious the technological progress.

\section{Empirical analysis}

\subsection{Determine reference sequence and comparison sequence}

Before doing grey association analysis, we must first determine the reference sequence and comparison sequence. According to the research objectives of this article, the proportion of the output value of high-tech products in the total industrial output value is taken as the reference sequence, denoted by $\mathrm{X} 0$; the seven factors affecting the allocation of regional science and technology resources are taken as the comparison sequence, denoted by $\mathrm{X} 1, \mathrm{X} 2 \ldots \mathrm{X} 7$, respectively.

\subsection{Dimensionless processing}

Due to the different connotations and units represented by each variable, the characterization data may have obvious differences in amplitude, and the data needs to be dimensionless before calculation. In this paper, the average transformation method is used to calculate the dimensionless data.

$x_{\mathrm{i}}^{(0)}(k)=\frac{\mathrm{x}_{i}(\mathrm{k})-\operatorname{Minx}_{\mathrm{i}}}{\operatorname{Max} x_{\mathrm{i}}-\operatorname{Minx}_{\mathrm{i}}}, \quad \mathrm{i}=0,1,2, \cdots, 7 ; k=1,2, \cdots, 20$

$X_{\mathrm{i}}^{(0)}=\left(x_{i}^{(0)}(1), x_{i}^{(0)}(2), \cdots, x_{i}^{(0)}(\mathrm{k})\right)^{T}$ is the dimensionless data sequence, and the formed matrix $\mathrm{A}$ is:

$$
A=\left(X_{0}^{(0)}, X_{1}^{(0)}, \cdots, X_{7}^{(0)}\right)=\left[\begin{array}{ccccc}
0 & 0 & 0.1569 & \cdots & 0 \\
0.0611 & 0.0107 & 0.0239 & \cdots & 0.0048 \\
\vdots & \vdots & \vdots & \vdots & \vdots \\
0.8919 & 0.9447 & 0.9521 & \cdots & 1 \\
1 & 1 & 1 & \cdots & 0.9243
\end{array}\right]
$$

comparison sequence one by one.

\subsection{Grey correlation calculation}

\subsubsection{Calculate difference sequence}

On the basis of non-dimensionalization, calculate the absolute value of the difference of each element corresponding to the reference sequence and the

$$
\begin{aligned}
& x_{i}^{(1)}(k)=\left|x_{0}^{(0)}(k)-x_{i}^{(0)}(k)\right|, i=1,2, \cdots, 7 ; k=1,2, \cdots, 20 \\
& X_{\mathrm{i}}^{(1)}=\left(x_{i}^{(1)}(1), x_{i}^{(1)}(2), \cdots, x_{i}^{(1)}(\mathrm{k})\right)^{T} \text {,available difference } \\
& \text { matrix B: }
\end{aligned}
$$




$$
B=\left(X_{1}^{(1)}, X_{2}^{(1)}, \cdots, X_{7}^{(1)}\right)=\left[\begin{array}{ccccc}
0 & 0.1569 & 0 & \cdots & 0 \\
0.0505 & 0.0372 & 0.0023 & \cdots & 0.0564 \\
\vdots & \vdots & \vdots & \vdots & \vdots \\
0.0527 & 0.0602 & 0.0181 & \cdots & 0.1081 \\
0 & 0 & 0 & \cdots & 0.0757
\end{array}\right]
$$

The maximum value of the data in matrix $\mathrm{B}$ is $\mathrm{M}=0.8907$,

Since the coefficients are not unique, the average method and the minimum value is $\mathrm{N}=0$.

can be used to calculate the gray correlation degree between each influencing factor and the reference sequence for overall

\subsubsection{Calculate the degree of gray correlation}

$r\left(x_{0}(k), x_{i}(k)\right)=\frac{N+\rho M}{x_{i}^{(1)}(k)+\rho M}, \rho \in(0,1) ; k=1,2, \cdots, 20 ; i=1,2, \cdots, 7$

comparison. $r\left(x_{0}, x_{i}\right)=\frac{1}{n} \sum_{k=1}^{n}\left(r\left(x_{0}(k), x_{i}(k)\right)\right.$

$\rho$ is the resolution coefficient, which is generally 0.5 .

Table 1 The gray correlation degree between the allocation of scientific and technological resources and technological progress in Guangdong Province

\begin{tabular}{ccc}
\hline Influencing factors & Grey relational degree & Rank \\
\hline X1 & & \\
\hline X2 & 0.7678 & 2 \\
X3 & 0.6899 & 6 \\
X4 & 0.8468 & 1 \\
X5 & 0.7600 & 3 \\
X6 & 0.7527 & 4 \\
X7 & 0.5071 & 7 \\
\hline
\end{tabular}

\subsection{Grey Relational Analysis Conclusion}

\subsubsection{The interactive relationship between the allocation of scientific and technological resources and technological progress is more obvious}

According to the grey correlation calculation results in Table 1, the correlations between the seven influencing factors of Guangdong's scientific and technological resource allocation and technological progress are all greater than 0.5 , of which only experimental development accounts for less than 0.6 of $R \& D$ expenditures, indicating that the situation of Guangdong's scientific and technological resource allocation Technological progress has a high degree of relevance, and the allocation of scientific and technological resources has a strong driving force for social technological progress. From the perspective of the scale of the allocation of scientific and technological resources, $\mathrm{R} \& \mathrm{D}$ expenditure and $\mathrm{R} \& \mathrm{D}$ personnel investment have the most significant impact on technological progress, which is consistent with the economic status and comprehensive innovation capabilities of Guangdong Province. From the perspective of the allocation structure of scientific and technological resources, basic researchexpenditures have contributed the most to technological progress, reflecting that basic research is the source of scientific and technological innovation.

\subsubsection{The intensity of R\&D investment is the mosost important factor influencing technological proress in Guangdong Province}

From the perspective of the order of relevance, the factor that has the greatest impact on the technological progress of Guangdong is the proportion of R\&D expenditure in GDP, that is, the intensity of R\&D expenditure. The gray correlation is as high as 0.8468. The two are interdependent, affect each other, and interact closely. The full-time equivalent of R\&D personnel, the proportion of basic research in $R \& D$ funding, and the proportion of applied research in R\&D funding are also above 0.7 , which also has a strong support effect on technological progress in Guangdong Province.

\section{REFERENCES}

1. Liang Lin, Li Qing, Liu bin. The allocation efficiency of provincial science and technology resources under environmental constraints: time and space pattern, evolution mechanism and influencing factors[J].China Science and Technology Forum,2019(6):125-135.

2. HSIEH C T,KLENOW P J. Misallocation and 
Manufacturing TFP in China and India[J]. The Quarterly Journal Economics,2007,124(4):1403-1448.

3. ADADI S, MOVAGHAR A, RAHMANI A M, et al. Marketbased grid resource allocation using new negotiation model[J]. Journal of Network and Computer Applications, 2013,36(1):543-565.

4. Shi Lei .The Status Quo and Countermeasures of
Resource Allocation of my country's Key S\&T Basic Conditions[J].Scientific Management Research , 2012,30(4):1-4.

5. $\mathrm{Su} \mathrm{Li}, \mathrm{Li}$ Guihua.On the Optimal Allocation of Science and Technology Resources and the Maximization of Effects[J].Chinese University Science and Technology, 2015 (3):12-15. 